\title{
Experimental and Numerical Analysis of The Used Hollow Slab
}

\author{
Xudong Hua ${ }^{1, a}$, Xingwei Xue ${ }^{1}$, Junlong Zhou ${ }^{1}$ and Hai Zhang ${ }^{1}$ \\ ${ }^{1}$ School of Civil Engineering, Shenyang Jianzhu University, Shenyang 110168, China
}

\begin{abstract}
The actual bearing capacity of a bridge in active service is crucial to the structure, but such data is generally difficult to obtain. In order to obtain the actual ultimate bending capacity of the used hollow slab, a destructive test of a hollow slab, which has been used ten years, has been carried out. Moreover, based on the experimental analysis of the material parameter data, a three-dimensional finite element nonlinear analysis model of the used hollow slab was established. Through the experiment and finite element analysis of the used hollow slab, the comparisons of the failure mode, crack propagating and ultimate bending capacity were focused on. The main conclusions obtained through the study are as follows: (1) Strand is a kind of stable prestressed material, which can maintain good mechanical properties for a long time; (2) The used hollow slab still maintains good ultimate bending capacity, although underwent a decreased rigidity due to long-term cumulative damage; (3) The total strain fracture model is qualified for simulating the nonlinearity of concrete material, and can obtain the ultimate bearing capacity of reinforced concrete structure effectively as well as simulates the development of cracks well.
\end{abstract}

\section{Introduction}

Hollow slab is one of the most commonly used forms of reinforced concrete bridges and prestressed concrete bridges in small span of $10 \sim 20 \mathrm{~m}$. It is named hollow slab because its section is wide, thin, and hollow[1].

Hollow slab bridge is simply supported beam bridge, which is suitable for mass production in factory and assembly-type construction. The hollow slab bridge is made up of multiple prefabricated beams. Between the main beams and the top filled with in situ concrete, the structure between the main beams is hinge and the up one is cast-in slab. Through hinge and cast-in slab, each prefabricated beam can withstand an external load as a whole.

Generally, bridge designers design and evaluate the bridges in accordance with the specifications which can only be suitable for the new bridges. For the bridges used some years, the actual carrying capacity is difficult to be effectively judged. For the bridges in service, the actual bearing capacity of a bridge in active service is crucial to the structure, but such data are generally difficult to obtain. Relevant data and researches are rare.

Li Hongzhi et al[2] conducted a destructive load test of a 10-year-old prestressed concrete hollow slab after replacing and repairing with two-layer carbon fiber. The ultimate load bending moment value of the nonreinforcement concrete hollow slab in the mid-span was $599.5 \mathrm{kN} \cdot \mathrm{m}$ and $871.75 \mathrm{kN} \cdot \mathrm{m}$ of the reinforcement one. The reinforcement efficiency coefficient reached 1.45 , which shows a good reinforcement effect.

Zhuo Jing et al[3] conducted a destructive test on a $10 \mathrm{~m}$ long hollow slab reinforced by unbonded prestress, which significantly improved the mechanical properties of the component in the elastic working phase and significantly improved the carrying capacity.

A prestressed concrete hollow slab beam bridge was used for full-scaled destructive test by FM Wang et al[4]. The law of deflection change, strain variation and crack propagation of the bridge were systematically discussed, as well as the failure process and mode. The results showed that the actual bearing capacity of the bridge was much higher than the theoretical value.

More often, attention has been paid to box beams[5,6]. The influence of actual carrying capacity of hollow slabs has not been the subject of comprehensive analysis. For this reason, research was undertaken by the authors, and described below.

In order to obtain the actual ultimate bending capacity of the used hollow slab, a destructive test of a hollow slab, which has been used ten years, has been carried out. More over, based on the experimental analysis of the material parameter data, a threedimensional finite element nonlinear analysis model of the used hollow slab was established. Through the experiment and finite element analysis of the used hollow slab, the comparison of the failure mode, crack propagation and ultimate bending capacity was focused on.

In this paper, a three-dimensional finite element model was established by Midas/FEA. It is an excellent civil engineering finite element analysis software, a large number of practical projects have got good results[7] by using it. In particular, Midas/FEA has obvious advantages in nonlinear analysis of concrete. Finally, conclusions regarding carrying capacity of hollow slabs were proposed.

*Corresponding author: ${ }^{a} 15998232953 @ 163 . c o m$ 


\section{Destructive Test}

\subsection{Overview of the old bridge}

The hollow slab bridge on the highway had been built for 10 years and its main span was $16 \mathrm{~m}$. The bridge vehicle load design grade was super-vehicle-20.

It can be seen from Figure 1 that there were 14 steel strands arranged under the single hollow slab, the stirrups were arranged with a spacing of $10 \mathrm{~cm}$ at the end of the support and the rest by $20 \mathrm{~cm}$.

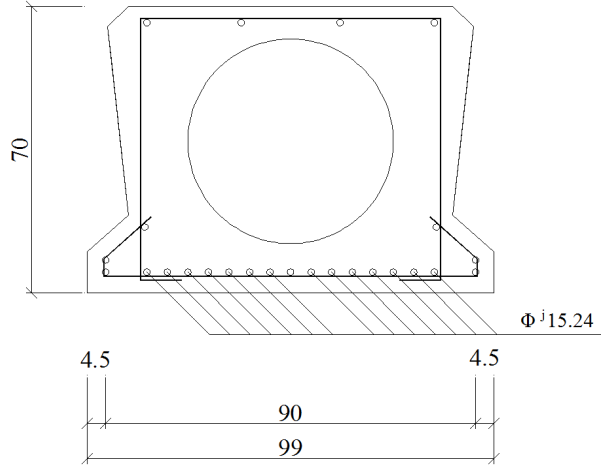

Figure 1. The section of the hollow slab (unit: $\mathrm{cm}$ ).

There were a total of five test beams numbered HS16-0, HS16-1, HS16-2, HS16-3, HS16-4. HS16-0 was used to determine the material properties of concrete and steel strand. HS16-1 HS16-4 were used to do load test. Figure 2 shows the actual old hollow slab.

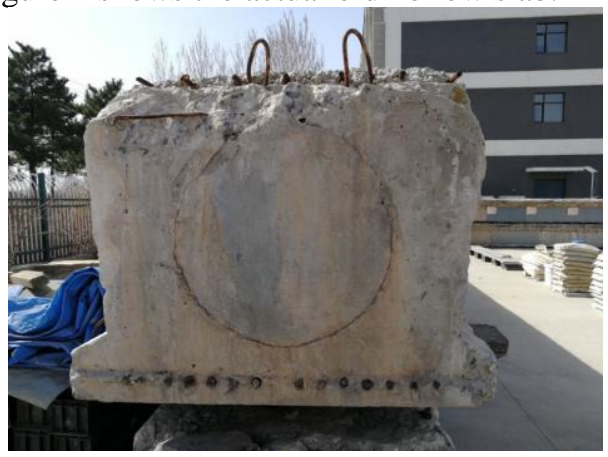

Figure 2. The actual old hollow slab.

The concrete grade of the main beam was $\mathrm{C} 40$. Three core samples $(\mathrm{d}=100 \mathrm{~mm})$ of the HS16-0 old hollow slab were Extracted. The compressive strength values were 55.31, 52.05 and 58.43 MPa respectively and the average value was 55.26 $\mathrm{MPa}$. From the actual measurement results we can see, as the age increasing, the strength of concrete gradually increases.

Tensile tests on the six strands (numbered PS01 PS06 respectively) of the HS16-0 old hollow slab were carried out to obtain the related performance parameters of the used steel strand, of which PS01 steel strand Line not measured complete data. The results of tensile tests show that no significant decrease in yield stress $(1450 \mathrm{MPa} \sim 1650 \mathrm{MPa})$ and ultimate tensile strength $(1890 \mathrm{MPa} \sim 1980 \mathrm{MPa})$ has been observed for the tenyear old strands in the old hollow slab. At the same time, it shows strand as prestressed reinforcement is a reliable and durable material.

\subsection{Destructive test}

As shown in Figure 3, sandbags were being hoisted one by one to the main beam by cranes, which were used to load all span of the $16 \mathrm{~m}$ long hollow slab.



Figure 3. Loading step by step.

As shown in Figure 4, strain gauges were attached to the bottom of the main beam to record the change of the strain during the loading process. At the same time, the vertical displacement of the main beam was measured by steel string displacement meter. In the loading process by sandbags, keep recording the strain, vertical displacement and perpendicular cracks of the hollow slab.

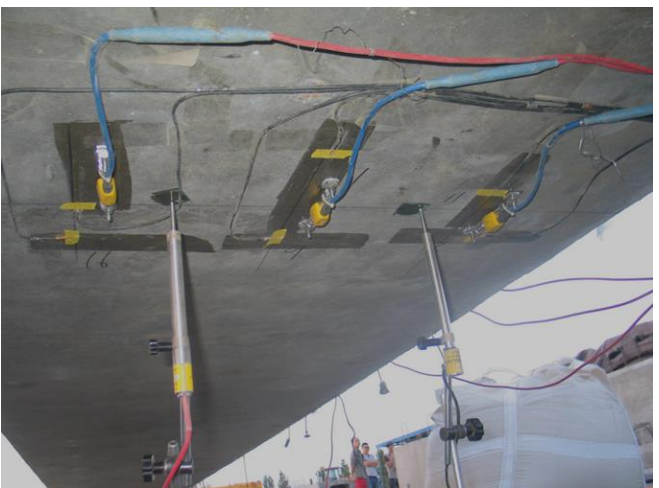

Figure 4. Installed strain, displacement sensors.

\section{Construction of FEA model}

In this paper, based on the concrete total strain crack model and the steel Von Mises constitutive model, a three-dimensional solid finite element model of the used hollow slab was established by using the generalpurpose software Midas/FEA.

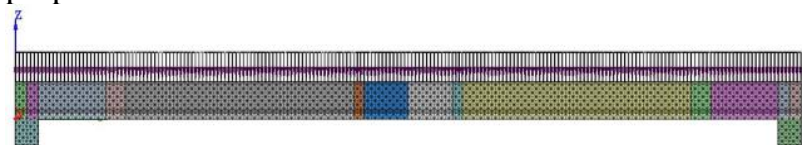

Figure 5. FEA model of the hollow slab.

The hexahedral solid element of Midas/FEA used to model has three translational degrees of freedom of each 
node. The whole girder was divided into a total of 7539 nodes and 131301 units. In order to prevent stress concentration in the main beam, elastic pads were established in the support. The main beam used simple constraint.

Calculated loads included structural self-weight, prestress and sandbag loads. The girder's weight density is $26.0 \mathrm{kN} / \mathrm{m}^{3}$.

The compressive property of the concrete total strain crack model was represented by the parabolic compression model, which is derived from the theory of fracture energy by Feenstra and determined by three characteristic values. The tensile strain characteristics of the concrete were simulated using the brittle model. When the tensile stress exceeds the tensile strength, the model no longer increases, and the resistance stress is zero.

The prestressed steel strands and the ordinary steel strands were simulated by the Von Mises model. This model is widely used in the analysis of metallic materials. The material constitutive parameters are relatively simple, and the hardening behavior for yield stress can be defined by multiple linear functions.

The prestressed tendons were modeled by the composition of rebar element and parent element. The advantage is that rebar nodes and element nodes needn't coupled, and the strain of the entity node can be mapped to the node of rebar unit, which can effectively calculate prestress loss.

The low-relaxation alloy steel of the tendons had a standard tensile strength of $1860 \mathrm{MPa}$. All prestressed tendons were stressed from both ends. The jacking stress of each tendon was $1395 \mathrm{MPa}$.

\section{Comparison and analysis of the test and calculation results}

\subsection{Analysis of ultimate bearing capacity of bending}

Through the information such as the span and the weight of the sandbags loaded on the main beam, the bending moment $M_{\text {mid }}$ caused by sandbags in the mid-span of the main beam can be calculated. Figure 6 shows the relationship of the mid-span bending moment $M_{\text {mid }}$ and the mid-span displacement.

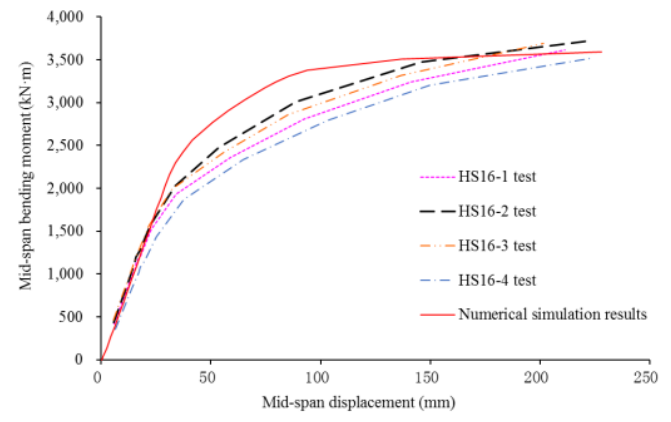

Figure 6. The load displacement curves of the mid-span.
The load displacement curves of the destructive test shows the flexural bearing capacity of the HS16-2 hollow slab is better than that of the other three hollow slabs, so we used it as the analysis object of the following research contents.

(1) The full-stage analysis of the used hollow slab under sandbag load in the destruction test.

At the initial stage of small load, the mid-span displacement of the used hollow slab basically maintains a positive proportional relationship with the load, indicating that the used hollow slab was in a elasticity working state. With the increase of sandbag load, when the $M_{\text {mid }}$ is more than $1571.40 \mathrm{kN} \cdot \mathrm{m}$, the load displacement curve shows a significant inflection point, the slope of the curve becomes smaller and the rigidity of the used hollow slab decreases gradually. When the load is terminated, the mid-span displacement is 221.5 $\mathrm{mm}$. The used hollow slab shows good ductility.

(2) Comparison of test and calculation results.

In general, the mid-span displacement obtained from the numerical simulation of the old hollow slab basically agrees with the results of the bending load test of the old hollow slab.

Flexible stage. At the stage of initial loading, the mid-span displacements and load are basically in proportion. The results of the numerical simulation are in good agreement with the test.

Cracking stage. With the load increases, the cracks appeared at the bottom of the used girder in the mid-span, the nonlinear characteristics gradually appeared. However, there is a certain difference between the experimental results and the numerical simulation. For the yield load value, the test load is $1571.40 \mathrm{kN} \cdot \mathrm{m}$, but the numerical simulation load is $2158.65 \mathrm{kN} \cdot \mathrm{m}$. As the used hollow slab had beared the load for a long time, the girder had some cracks and a certain degree of damage, which led to the decrease of the yield strength and rigidity of the hollow slab and the certain residual strain.

Stage of ultimate capacity. The results of numerical simulation are basically consistent with load test results of the used hollow slab. The ultimate flexural capacity of the numerical simulation is $3591.00 \mathrm{kN} \cdot \mathrm{m}$, the corresponding vertical displacement is $228.0 \mathrm{~mm}$; the ultimate flexural capacity of the test result is 3715.70 $\mathrm{kN} \cdot \mathrm{m}$ and the corresponding vertical displacement is $221.5 \mathrm{~mm}$. The difference between the numerical simulation and the test is only $3.5 \%$ in ultimate flexural capacity and $2.9 \%$ in vertical displacement. This shows that the used hollow slab still maintains a good ultimate flexural capacity and ductility. At the same time, the numerical simulation shows that the total strain model can well simulate the nonlinear behavior of the concrete material.

\subsection{The Development of Cracks}

The cracks were signed and measured with the crack observation instrument. Crack pattern characteristics for both the test and the numerical simulation are presented in Figure $7 \& 8$. 


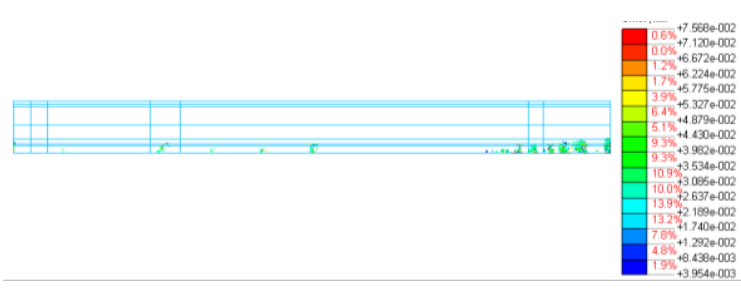

Figure 7. Numerical simulation of the cracks width of the main beam when the longitudinal steel yields (half span, unit: $\mathrm{mm}$ ).

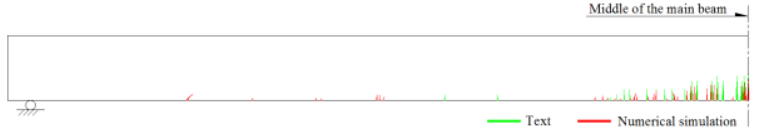

Figure 8. Comparison of cracks in the main beam (half span, unit: $\mathrm{mm}$ ).

The cracks were formed as described below. In the first stage of loading at about $230 \mathrm{kN}$, perpendicular cracks appeared in the middle of the span in every beam.

As the load increased, the number of the mid-span cracks gradually increased, in the same time the crack width also gradually expanded, and the cracks mainly distributed in the mid-span (Figure 7). The cracks gradually spread to both ends of the main beam

When the load was close to the yield load $(2158.65$ $\mathrm{kN} \cdot \mathrm{m}$ ), the vertical main cracks were formed in the midspan, while the main cracks gradually developed upwards and expanded to the L/4 and 3L/4 on both sides of the used hollow slab beam. When the load reached the yield load of $2158.65 \mathrm{kN} \cdot \mathrm{m}$, the cracks width increased rapidly, reaching $0.08 \mathrm{~mm}$ (Figure 7 ).

However, due to the long-term damage of the used hollow slab caused by the loads of the automobile and so on, there were subtle cracks in the main beam. Therefore, during the loading process, both the development speed and the width of the cracks were larger than those of the numerical simulation. Figure 8 shows a comparison of experimental and numerical simulations of the cracks development.

\section{Conclusions}

This paper has analyzed the flexural bearing capacity of the $16 \mathrm{~m}$ used hollow slabs. Based on the experimental data obtained from the analysis of the material parameters, a three-dimensional finite element nonlinear analysis model of the old hollow slab has been established using the total strain crack model. In this paper, the actual material properties of the old hollow slab has been measured, and the ultimate bearing capacity and the crack development of the test and the numerical simulation has been compared. The main conclusions are as follows:

(1) Steel strand is a kind of prestressed material with stable performance and can maintain good prestress effect for a long time. After 10 years of use, its mechanical properties are still relatively stable;

(2) After 10 years of operation, due to long-term cumulative damage of the old hollow slab, its stiffness has decreased, but it still maintains a good ultimate bearing capacity that can meet the requirements of use;
(3) The total strain crack model can well simulate the nonlinearity of concrete materials, and can efficiently determine the ultimate bearing capacity of reinforced concrete structures and accurately simulate the development of cracks.

\section{References}

1. X Y Liu. Beam bridge (Second Edition) (Beijing: China Communications Press, 2011)

2. H Z Li, F Shang. Prestressed concrete hollow slabs bridge reinforcement scheme J. Highway. 2007(08):38-40

3. J Zhuo, F W Huang, T N Li. Test research on fast consolidation of hollow slabs with prestressed carbon fiber tape J. Technology of Highway and Transport. 2010(05):75-79

4. F M Wang, S Z Kang, Y C Cai, X L Li. Destructive test study of a prestressed concrete hollow slab beam bridge. Geohunan International Conference. 2011(404):57-64

5. X W Xue, J W Wu, J L Zhou, H N Li. A Finite segment method for skewed box girder analysis J. Mathematical Problems in Engineering. 2018(1):113

6. J E Rodriguez-Sanchez, A Rodriguez-Castellanos, F Perez-Guerrero. Shot peening wffect on fatigue crack repaired weldments J. Advances in Materials Science and Engineering. 2017:1-11

7. X W Xue, J L Zhou, X D Hua, H N Li. Analysis of the generating and influencing factors of vertical cracking in abutments during construction J. Advances in Materials Science and Engineering. 2018(6):1-13

8. B Sun. Nonlinear finite element analysis of corroded RSC compressive and flexural members J. Journal of Xi'an University of Architecture \& Technology. 2005(03):326-331

9. M S Xiang, X L Zhao. Analysis and evaluation of bearing capacity of old prestressed concrete bridge $\mathrm{J}$. Transportation Scicncc \&Technology. 2017(01):7678

10. G Q Gu, D Y Li, J M Huang, S H Li. Experimental study on flexural behavior of corroded reinforced concrete hollow slab beam J. Technology of Highway and Transport. 2007:83-86

11. S P Corgnati, A Kindinis. Thermal mass activation by hollow core slab coupled with night ventilation to reduce summer cooling loads J. Building \& Environment. 2007,42(9):3285-3297 